\title{
Battery Voltage and Room Temperature Monitoring using Website with Warning Notification for Pagardewa Compressor Station
}

\author{
Heru Supriyono $^{1}$, Saiful Arifin Wahyu Wibowo ${ }^{2}$ \\ ${ }^{1}$ Universitas Muhammadiyah Surakarta, Indonesia, Heru.Supriyono@ums.ac.id \\ ${ }^{2}$ Universitas Muhammadiyah Surakarta, Indonesia, D400160065@student.ums.ac.id
}

\begin{abstract}
The battery voltage level is a critical parameter for Uninterruptible Power Supply (UPS) employed by Pagardewa compressor station. If batteries are faulty it could cause station shutdown. The UPS consists of batteries which should have a certain voltage level and it is placed in the temperature-specified battery room. The main purpose of this article is to measure battery voltage and room temperature then to display it continuously on a website and send notification messages if the voltage or temperature value is beyond the specified range. The system has been developed based on the Arduino Mega microcontroller which includes wifi for data communication. As a prototype, the monitoring system was applied to 8 of 108 batteries of the UPS during its daily normal operation. The voltage measurement test results showed that the monitoring system has an average measurement difference of $0.0082 \mathrm{~V}$ or equal to $0.1896 \%$ when compared to that of by a commercial measuring instrument while the temperature measurement results in the battery room have a difference of $0.6{ }^{\circ} \mathrm{C}$ or equal to $3.03 \%$. Hence, this prototype is potentially to be enhanced for all 108 batteries of UPS in order to prevent station shutdown.
\end{abstract}

Key words :Battery monitoring, battery management system, battery voltage monitoring, uninterruptible power supply.

\section{INTRODUCTION}

Uninterruptible Power Supply (UPS) is often used to supply electrical power for critical equipment such as control instrumentation so that if the power quality is less than the specified value it can cause interference with the system or even stop completely. Pagardewa compressor station is a natural gas pressure boosting station. This station consists of 5 main areas, including the Motor Control Center (MCC) building area. In the MCC building area there is a battery room that supplies power to the UPS on critical equipment namely the Distributed Control Systems (DCS) panel. UPS in this area has 108 batteries. This DCS panel is an important piece of equipment and if there is lack of power supply it can cause unit or station shutdown. Therefore, routine maintenance on the battery is always done by checking the battery voltage because voltage is the main parameter to measure in the battery of UPS fault detection [1]. Checking activities carried out by manual measurement using a multimeter within a period of once a month. The weakness of this method is that the battery fault could not be detected earlier because the condition of the battery voltage is only known in a period of one month or when a disturbance has occurred. Checking the battery voltage manually cannot provide battery voltage information continuously.

Electronic systems with internet of things (IoT) technology has potential to be applied for monitoring of physical variables and have attracted extensive interest of researchers for broad applications for example for water volume monitoring [2], location and conditions of soldier monitoring [3], environmental quality of chicken coop monitoring [4] and patient with sleep-disorder monitoring [5].

Battery state of health (SOH) monitoring has attracted extensive interest among researchers. Researchers have investigated the way how to monitor the level of battery $\mathrm{SOH}$ based on some parameters for example its charging time [6], its charging voltage curve [7] and its state of charge (SOC) [8]. Not only for lead-acid based or Lithium based battery but $\mathrm{SOH}$ monitoring also was proposed for photovoltaic based battery [9]. Research on battery monitoring was commonly performed in laboratory experimental environments such as in [10] and [11]. Besides, battery health could be monitored during its operation [12]. For application in the UPS, most published works on UPS monitoring systems were also performed in the laboratory experimental basis for example research resulted in [13] and [14] and also other similar publications. The publication on battery of UPS monitoring on real-world operation is still limited. In actual operation, battery health conditions would be related to the actual dynamic of the operational environment [15].

This paper discusses the development, calibration testing, and actual testing phases of the proposed system for monitoring battery voltage of UPS while it was in daily normal operation and battery room temperature at Pagardewa compressor station. The objectives of this study are to measure battery 
voltage and room temperature then display it continuously on a website and send notification messages if the voltage or temperature value is beyond the specified range. Although temperature of battery surface is also could be considered as indication of battery fault [16], however, in this publication the battery room temperature was chosen to monitor since the UPS at Pagardewa compressor station is employed at certain temperature-specified room.

\section{METHOD}

\subsection{System Architecture}

Parameters which could be monitored in order to understand the level of battery SOH involving voltage of its terminal, temperature of its surface, and its current [17]. Of these parameters, based on actual need in Pagardewa compressor station, in this paper only the most primary parameter, i.e. battery terminal voltage of UPS would be monitored together with battery room temperature. It is essential to monitor the temperature of the battery room in order to make sure that the battery is working in the proper environment. Based on the maintenance manual book, the battery has its own optimal working temperature, too cold temperature would decrease battery capacity but too hot temperature would decrease battery life.

The battery voltage monitoring system was developed using RobodynArduino Mega + wifi as a data processor and communication media. RobodynArduino Mega + Wifi will process data from voltage and temperature sensors then send the processed data to the database and Telegram application and display the data through the website and on the $16 \times 2$ LCD. When the parameter value exceeds the limit, RobodynArduino Mega + Wifi will send a warning message through the social media application software robot of Telegram application (bot Telegram). The system architecture can be seen in Figure 1. Wifi was chosen to be used for transmitting data processed by Arduino to the smartphone, database and website because it has higher data communication speed compared to Bluetooth used in [18]. As reported in [19], the use of a database and website for battery monitoring system will provide a user interface which is helpful to get information of battery condition easily. Also, it is possible to add more information on the website of battery monitoring display for example adding battery current position by using Global Positioning Systems (GPS) coordinate [20].

The system architecture shown in Figure 1 is different from that reported by other researchers for example research result in [21] especially in the use of Telegram application warning notification. The use of website for displaying parameters of battery $\mathrm{SOH}$ was also proposed by previous researchers for example in [22] and it facilitating user to understand the condition of battery graphically however there was no chart showing history of voltage reading continuously.
The system architecture in Figure 1 was implemented in the hardware circuit depicted in Figure 2. The battery output voltage is measured using an analogue input pin that is already contained in the Arduino Mega. The total number of batteries in the Pagardewa compressor UPS are 108 batteries. Of these, the monitoring system will be implemented on 8 batteries as a prototype or proof of concept. Therefore to measure voltage of 8 batteries, a 16 channel relay module is needed. This relay module has three main pins as follows: VCC pin is for connecting to reference voltage, GND pin is for connecting to ground, and pins 1 to 16 are for sending data/command.

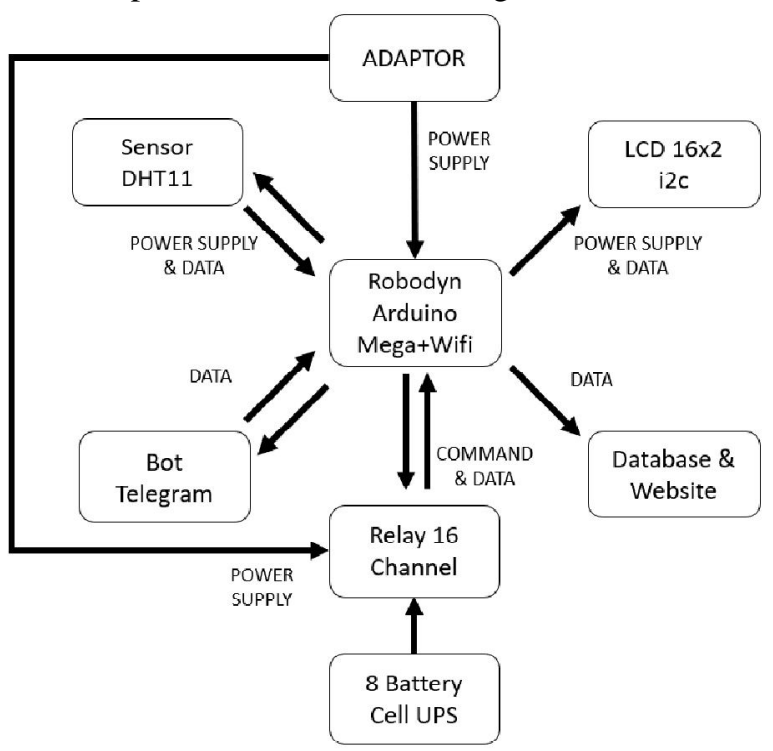

Figure 1: System architecture of proposed monitoring system

In each relay there are 3 terminals namely common, normally close (NC) and normally open (NO) terminals. In the absence of a command input trigger (means battery voltage in the range of specified values according to the standard), the common terminal will be connected to a $\mathrm{NC}$ terminal so that Robodyn Arduino Mega measures the voltage and displays it on the LCD then sends it to the database as well as the website. Then, when there is trigger relay input command in a low level position (the battery voltage is outside the specified value range) the common terminal will be connected to the NO terminal so that Robodyn Arduino Mega will measure the voltage, send it to the database, display on the website and send the message warning notifications using the robot software of Telegram application.

Notification feature of monitoring systems was reported to be useful to mitigate the potential of fatal situations [23, 24] where short message service (SMS) of global system module (GSM) networks was used to send warning messages in the monitoring system of a distribution transformer. Similar system but with the addition of phase preventer was proposed in [25]. Compared to SMS, the use of Telegram application has advantages such as simpler and cheaper since it does not need any additional hardware modul for GSM sim card and also it does not need to spend extra recurring cost for maintaining credit balance of GSM network. 


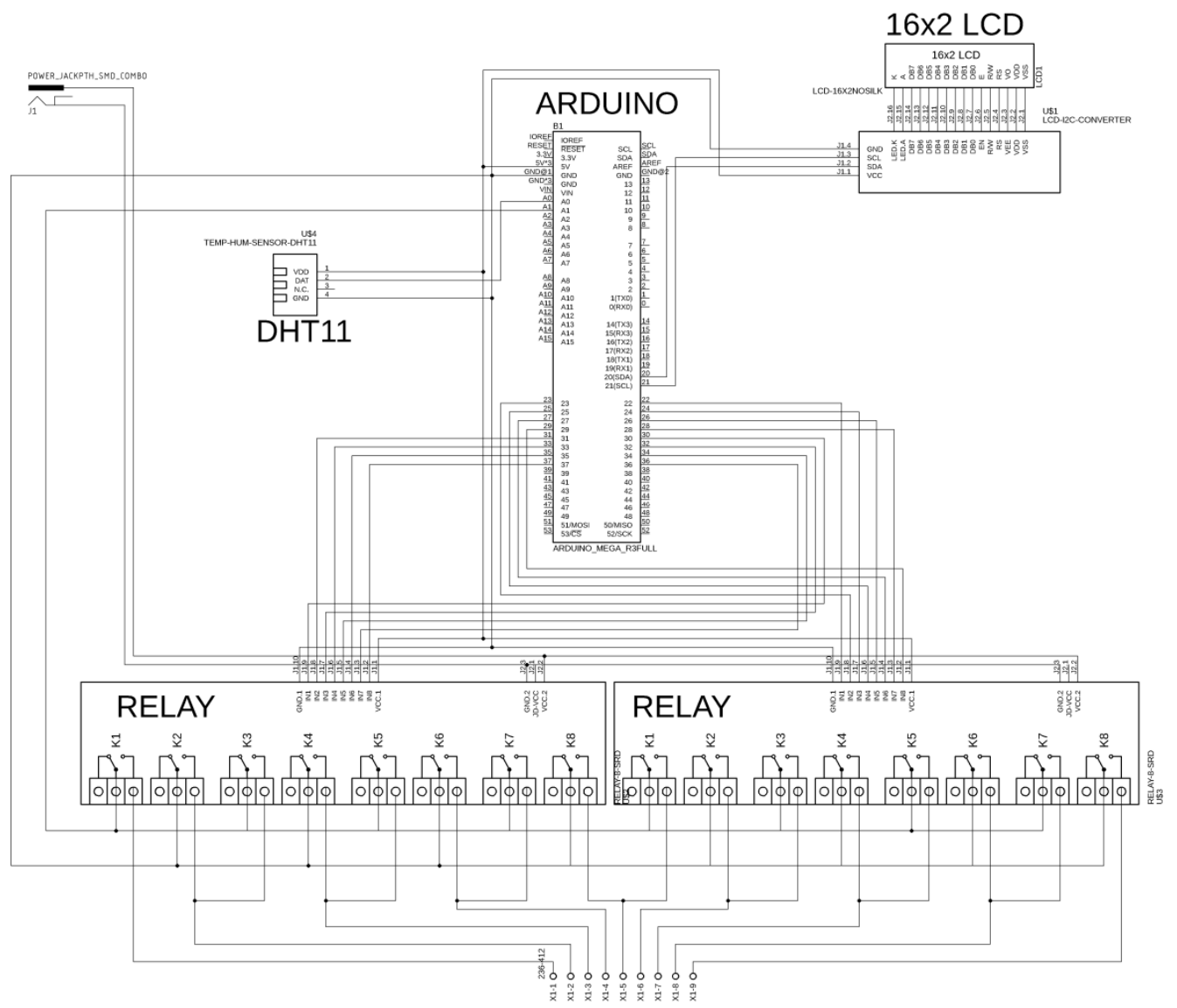

Figure 2: Schematic diagram of hardware circuit of proposed monitoring system

Temperature and humidity values in the battery room are measured using the DHT11 sensor. The DHT11 sensor has 3 pins namely VCC pin for connecting to reference voltage, pin data for sending data to Arduino Mega + Wifi, and GND pin for connecting to ground. Liquid Crystal Display (LCD) is an electronic display that is used to display system measurement results. In this paper a 16x2 sized LCD was used which means that it can display 16 characters horizontally and two characters vertically. Normally the LCD module is controlled in parallel so it requires many pins on the controller side. To save pins and space, an additional module, I2C converter, is used so that there are only two data cable lines needed namely SDA and SCL which are connected to D20 and D21 pins of Arduino Mega respectively.

\subsection{Software Design and Configuration}

There are three kinds of software developed or configured in the monitoring systems namely: (1) the main software is the software of ArduinoMega+wifi, (2) database and website for storing and displaying the measured data on the computer or smartphone, and (3) Telegram bot for displaying measured data and warning notification using Telegram text message. The general computation process of the main program in ArduinoMega+wifi, presented in Figure 3, can be explained as follows. First, Arduino Mega reads and processes the data of voltage, and temperature sensors. Secondly, Arduino Mega sends all processed data to database, website, and Telegram in wireless using wifi. Besides, the measured data also would be displayed in LCD. Finally, if there is parameter value outside the determined range, Arduino Mega will send a warning notification to the Telegram application.

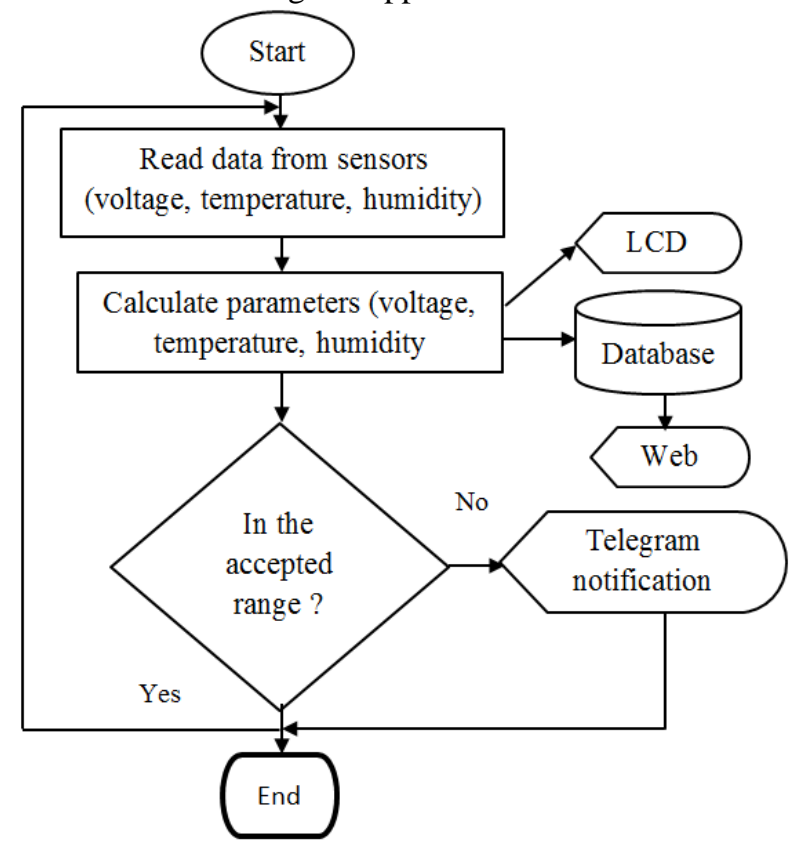

Figure 3: Flowchart representing main program in Arduino 


\section{RESULTS AND DISCUSSION}

\subsection{Actual Resulted Hardware Circuit}

To protect against collisions and water splashes, all hardware sets are included in a 2-level acrylic box as can be seen in Figure 4 and 5. At the first level there is a relay module component. At the second level there are components such as Arduino Mega + Wifi, LCD, DHT11, and power supply modules. This monitoring system hardware circuit gets a $5 \mathrm{~V}$ voltage that comes from the power supply module sourced from the power adapter.

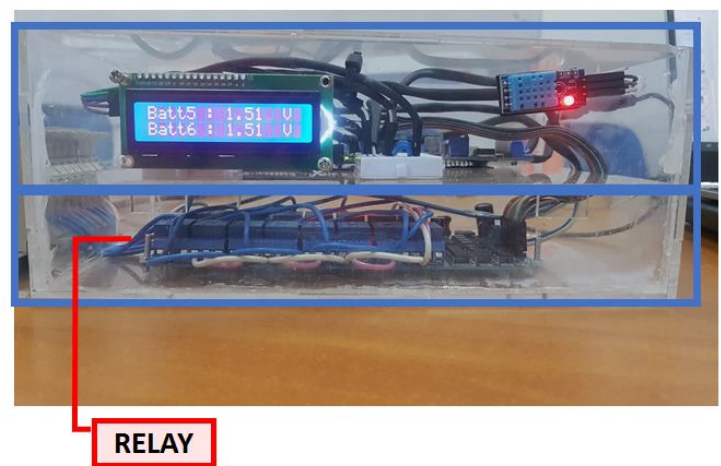

Figure 4: Side view of actual hardware circuit

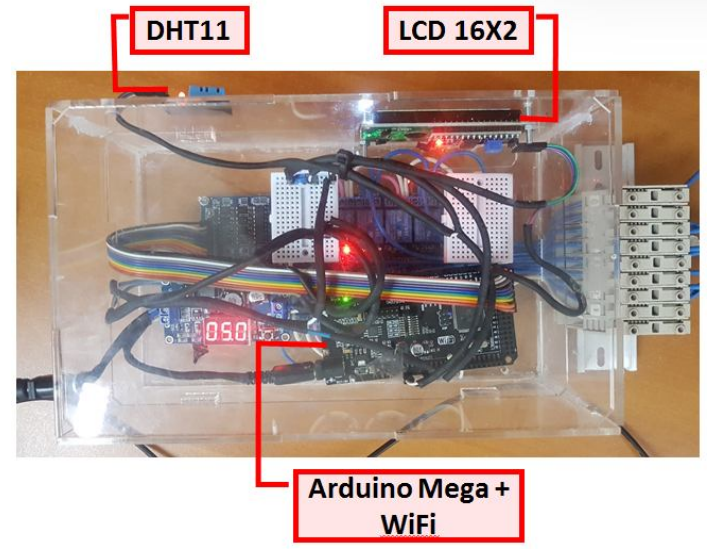

Figure 5: Top view of actual hardware circuit

\subsection{Calibration Process and Voltage Test Result}

The calibration step is carried out to ensure the data generated by the sensor to be processed by the Arduino microcontroller is valid. For analogue sensor input, the first step of calibration is to measure the amount of voltage between the $5 \mathrm{~V}$ pin and GND on Arduino using a multimeter. After measurement results are obtained, these results are then used for the conversion process in the program. Furthermore, to determine the accuracy of voltage measurement results by the monitoring system, validation process is carried out by measuring the power supply voltage using the proposed telemonitoring system and then comparing it with that of commercial measuring instruments namely Fluke 287 multimeter as can be seen in Table 1. The difference in measurement results is expressed as a measurement difference $(\Delta)$ which can be calculated using (1) while the value of the measurement difference expressed in percent $(p)$ can be calculated with (2).

Table 1: Calibration testing results of voltage measurement

\begin{tabular}{|c|c|c|c|c|}
\hline Voltage (V) & $c(\mathbf{V})$ & $a(\mathbf{V})$ & $\Delta(\mathbf{V})$ & $p(\%)$ \\
\hline \multirow[t]{5}{*}{0.5} & 0.4999 & 0.49 & 0.0099 & $1.98 \%$ \\
\hline & 0.4999 & 0.49 & 0.0099 & $1.98 \%$ \\
\hline & 0.4991 & 0.49 & 0.0091 & $1.82 \%$ \\
\hline & 0.4991 & 0.49 & 0.0091 & $1.82 \%$ \\
\hline & 0.4991 & 0.49 & 0.0091 & $1.82 \%$ \\
\hline \multirow[t]{5}{*}{1.0} & 0.9986 & 0.99 & 0.0086 & $0.86 \%$ \\
\hline & 0.9987 & 0.99 & 0.0087 & $0.87 \%$ \\
\hline & 0.9987 & 0.99 & 0.0087 & $0.87 \%$ \\
\hline & 0.9987 & 0.99 & 0.0087 & $0.87 \%$ \\
\hline & 0.9987 & 0.99 & 0.0087 & $0.87 \%$ \\
\hline \multirow[t]{5}{*}{1.5} & 1.4996 & 1.49 & 0.0096 & $0.64 \%$ \\
\hline & 1.4997 & 1.49 & 0.0097 & $0.65 \%$ \\
\hline & 1.4996 & 1.49 & 0.0096 & $0.64 \%$ \\
\hline & 1.4995 & 1.49 & 0.0095 & $0.63 \%$ \\
\hline & 1.4995 & 1.49 & 0.0095 & $0.63 \%$ \\
\hline \multirow[t]{5}{*}{2.0} & 1.9993 & 2.00 & 0.0007 & $0.04 \%$ \\
\hline & 1.9992 & 2.00 & 0.0008 & $0.04 \%$ \\
\hline & 1.9992 & 2.00 & 0.0008 & $0.04 \%$ \\
\hline & 1.9992 & 2.00 & 0.0008 & $0.04 \%$ \\
\hline & 1.9993 & 2.00 & 0.0007 & $0.04 \%$ \\
\hline \multirow[t]{5}{*}{2.5} & 2.4985 & 2.51 & 0.0115 & $0.46 \%$ \\
\hline & 2.4984 & 2.51 & 0.0116 & $0.46 \%$ \\
\hline & 2.4985 & 2.51 & 0.0115 & $0.46 \%$ \\
\hline & 2.4985 & 2.50 & 0.0015 & $0.46 \%$ \\
\hline & 2.4986 & 2.51 & 0.0114 & $0.46 \%$ \\
\hline \multirow[t]{5}{*}{3.0} & 2.9994 & 3.01 & 0.0116 & $0.39 \%$ \\
\hline & 2.9994 & 3.02 & 0.0206 & $0.69 \%$ \\
\hline & 2.9949 & 3.02 & 0.0251 & $0.84 \%$ \\
\hline & 2.9995 & 3.01 & 0.0105 & $0.35 \%$ \\
\hline & 2.9995 & 3.02 & 0.0205 & $0.68 \%$ \\
\hline \multirow[t]{5}{*}{3.5} & 3.4986 & 3.52 & 0.0214 & $0.61 \%$ \\
\hline & 3.4987 & 3.52 & 0.0213 & $0.61 \%$ \\
\hline & 3.4987 & 3.52 & 0.0213 & $0.61 \%$ \\
\hline & 3.4987 & 3.52 & 0.0213 & $0.61 \%$ \\
\hline & 3.4987 & 3.52 & 0.0213 & $0.61 \%$ \\
\hline \multirow[t]{5}{*}{4.0} & 3.9990 & 4.02 & 0.021 & $0.53 \%$ \\
\hline & 3.9990 & 4.02 & 0.021 & $0.53 \%$ \\
\hline & 3.9990 & 4.02 & 0.021 & $0.53 \%$ \\
\hline & 3.9991 & 4.02 & 0.0209 & $0.52 \%$ \\
\hline & 3.9991 & 4.02 & 0.0209 & $0.52 \%$ \\
\hline \multicolumn{3}{|c|}{ Minimum } & 0.0007 & $0.04 \%$ \\
\hline \multicolumn{3}{|c|}{ Maximum } & 0.0251 & $1.98 \%$ \\
\hline \multicolumn{3}{|c|}{ Average } & 0.0122 & $0.69 \%$ \\
\hline
\end{tabular}

$$
\begin{gathered}
\Delta=|c-a| \\
p=\frac{\Delta}{c} \times 100 \%
\end{gathered}
$$

Where $\Delta$ is measurement difference, $c$ is measurement result using commercial instrument, $a$ is measurement result using developed monitoring system, and $p$ is measurement 
difference value stated in percent. The power supply voltage level used in the testing process were $0.5,1,1.5,2,2.5,3,3.5$ and $4 \mathrm{~V}$ where there were five measurements conducted for every voltage level so that there were 80 measurement data in total. The test results in Table 1 showed that the proposed telemonitoring systems was able to measure voltage with measurement difference average was equal to $0.0122 \mathrm{~V}$ or $0.69 \%$ with the highest error $1.98 \%$ and the lowest error $0.04 \%$ compared to measurement results of Fluke 2287 multimeter. These results suggested that the voltage measurement results of proposed telemonitoring system are inline with commercial measuring instrument.

\subsection{Calibration Process and Temperature Test Results}

Temperature measurement test is done to determine the performance of the DHT11 sensor and Arduino Mega microcontroller. The tes result is presented in Table 2.

Table 2: Calibration of temperature measurement

\begin{tabular}{|c|c|c|c|c|}
\hline Room & $c\left({ }^{\circ} C\right)$ & $a\left({ }^{\circ} \mathrm{C}\right)$ & $\Delta\left({ }^{\circ} C\right)$ & $p(\%)$ \\
\hline \multirow{5}{*}{$\begin{array}{l}\text { Workshop } \\
30{ }^{\circ} \mathrm{C}\end{array}$} & 28.7 & 29 & 0.30 & $1.05 \%$ \\
\hline & 28.4 & 28 & 0.40 & $1.41 \%$ \\
\hline & 28.4 & 28 & 0.40 & $1.41 \%$ \\
\hline & 28.2 & 28 & 0.20 & $0.71 \%$ \\
\hline & 28.2 & 28 & 0.20 & $0.71 \%$ \\
\hline \multirow{5}{*}{$\begin{array}{l}\text { Office: } \\
25{ }^{\circ} \mathrm{C}\end{array}$} & 25.1 & 25 & 0.1 & $0.40 \%$ \\
\hline & 25.2 & 25 & 0.2 & $0.79 \%$ \\
\hline & 25.2 & 25 & 0.2 & $0.79 \%$ \\
\hline & 25.4 & 25 & 0.4 & $1.57 \%$ \\
\hline & 25.3 & 25 & 0.3 & $1.19 \%$ \\
\hline \multirow{5}{*}{$\begin{array}{l}\text { Meeting: } 30 \\
{ }^{o} \mathrm{C}\end{array}$} & 27.8 & 28 & 0.2 & $0.72 \%$ \\
\hline & 27.4 & 27 & 0.4 & $1.46 \%$ \\
\hline & 27.0 & 27 & 0 & $0.00 \%$ \\
\hline & 26.6 & 26 & 0.6 & $2.26 \%$ \\
\hline & 27.6 & 27 & 0.6 & $2.17 \%$ \\
\hline \multirow{5}{*}{$\begin{array}{l}\text { Meeting: } 25 \\
{ }^{o} \mathrm{C}\end{array}$} & 24.9 & 24 & 0.9 & $3.61 \%$ \\
\hline & 24.3 & 24 & 0.3 & $1.23 \%$ \\
\hline & 24.2 & 24 & 0.2 & $0.83 \%$ \\
\hline & 24.2 & 24 & 0.2 & $0.83 \%$ \\
\hline & 24.1 & 24 & 0.1 & $0.41 \%$ \\
\hline \multicolumn{3}{|c|}{ Minimum } & 0.0000 & $0.00 \%$ \\
\hline \multicolumn{3}{|c|}{ Maximum } & 0.9000 & $3.61 \%$ \\
\hline \multicolumn{3}{|c|}{ Average } & 0.3100 & $1.18 \%$ \\
\hline
\end{tabular}

The validation process is carried out by measuring the temperature using a telemonitoring system developed based on the DHT11 sensor and comparing the results of these readings with the measurement results with a commercial temperature measuring instrument, the Fluke 568 infrared thermometer. The test was carried out in the room with air conditioner (AC) facilities. There were three rooms used for testing, namely the workshop room, office room, and meeting room. At the time of testing, the monitoring system was placed on one of the available tables in the room. The temperature in the test room was determined by changing the AC temperature settings equal to $30{ }^{\circ} \mathrm{C}$ and $25{ }^{\circ} \mathrm{C}$. Of every room, for every temperature value there were five measurement comparisons conducted. In the temperature test, the average result of measurement difference was $0.31{ }^{\circ} \mathrm{C}$ or equal to $1.18 \%$ with the highest difference value was $3.61 \%$ and the lowest was $0.00 \%$.

\subsection{Overall Monitoring System Test Results}

The experimentation set up can be explained as follows. The monitoring system was placed in the battery room. Then the system was connected to 8 batteries for implementation testing, i.e. battery number 61 to 68 of UPS A. The specification of the batteries is $2 \mathrm{~V}, 420 \mathrm{Ah} / 10 \mathrm{~h}$. After that, the monitoring system measured temperature and humidity of battery room as well as voltage level of batteries number 61-68 simultaneously. Next, all the measured data were sent to the database, web, and Telegram application as well as displayed in a LCD with the period of 15 minutes. Finally, the voltage and temperature measurement data of the monitoring system were compared to those of a commercial measuring instrument used daily in Pagardewa compressor station.

The temperature of battery room and voltage of every battery measured by the monitoring system were displayed in the website continuously and graphically as can be seen in Figure 6. The monitoring system is equipped with detailed information of year, month, day, hour, minutes and second which are stored in the database as well as displayed in the web page (for the $\mathrm{x}$-axis) in order to facilitate real time monitoring and data recording especially for maintenance purposes. This detailed information presentation is different from previous research results in [26] where the data were sent using SMS technology and displayed on a mobile phone in the form of text not graphical. The overall monitoring system testing was conducted in Pagardewa compressor station on a normal operational day. The battery voltage based on the manual book is equal to $2.23 \mathrm{~V}$ in float condition with inverter input is in the range between 187 and $264 \mathrm{~V}$. So, the monitoring system used battery voltage normal range between 1.9 and $2.4 \mathrm{~V}$ for fault detection basis and send notification. Based on the manual book, battery room temperature should be around $20{ }^{\circ} \mathrm{C}$ so that monitoring system used temperature values between $14{ }^{\circ} \mathrm{C}$ and $26{ }^{\circ} \mathrm{C}$ as normal range for producing a warning notification.

The monitoring system sends the data to Telegram in the period of one hour. After data were sent, the user would be able to check the latest parameter value by sending a message command of the Telegram application as can be seen in Figure 7(a). If there is a measured parameter value beyond the expected range, then the monitoring system sends the notification message to the Telegram application as can be seen in Figure 7(b) where notification would be sent continuously every 75 seconds until the problem is solved. This results is encouraging for further development for example the use of a website for controlling the charging process of batteries such as used for controlling a motor in [27]. 


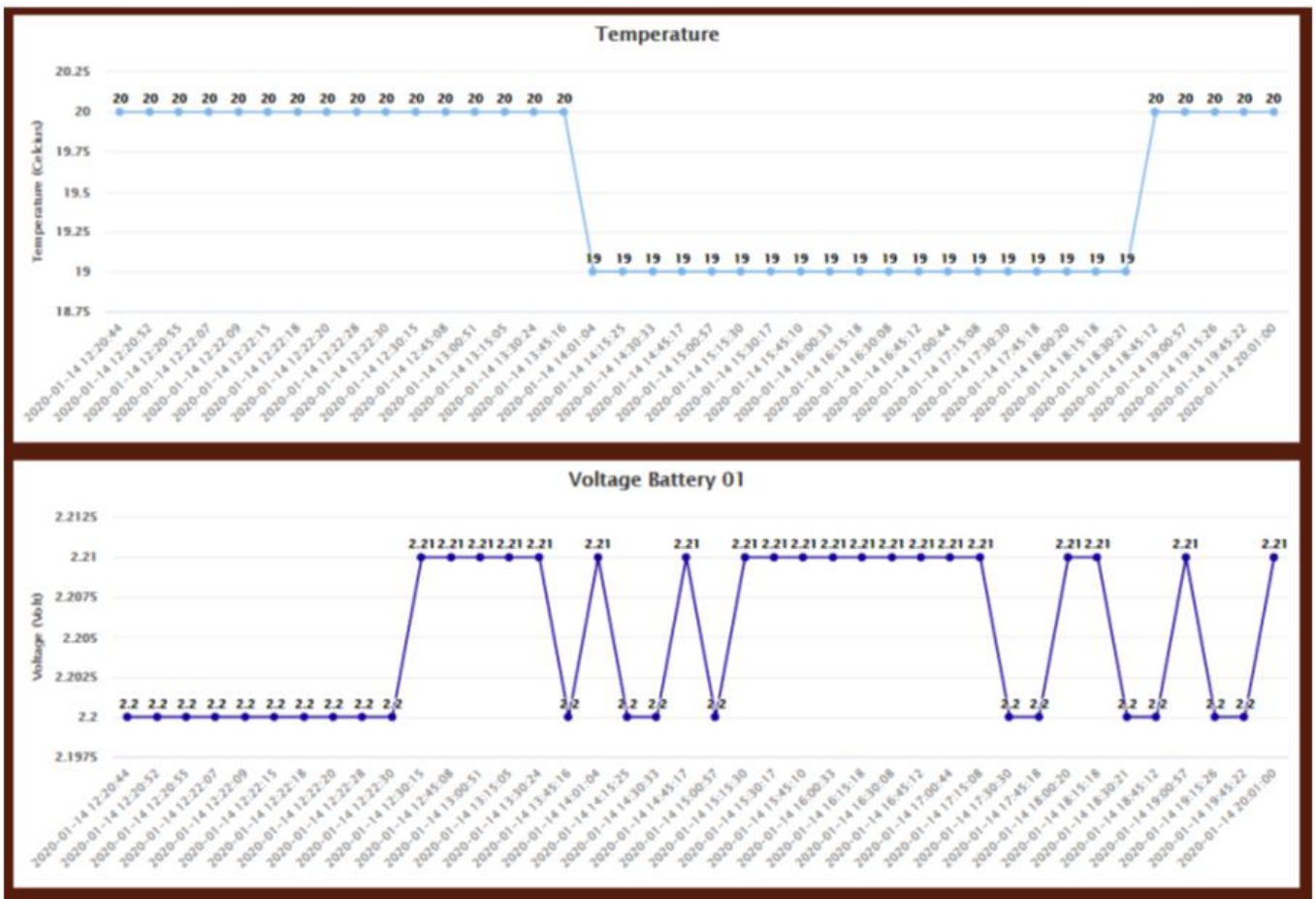

Figure 6: Display of temperature and voltage measurement in the website continously and graphicaly

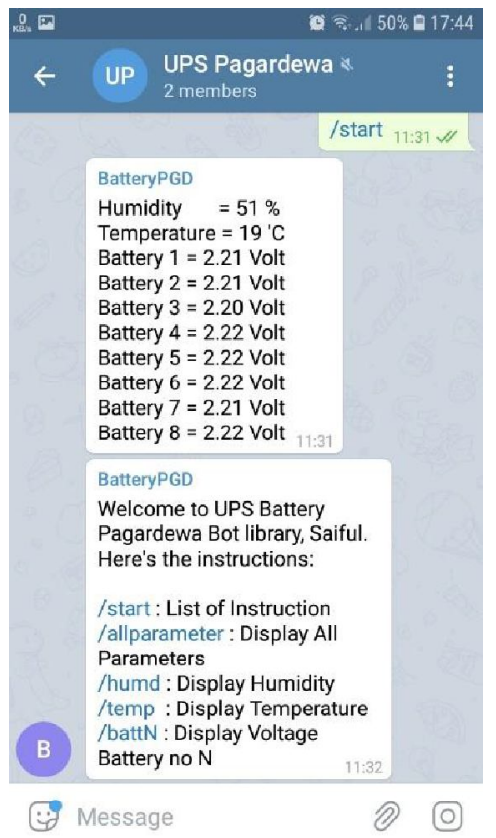

(a)

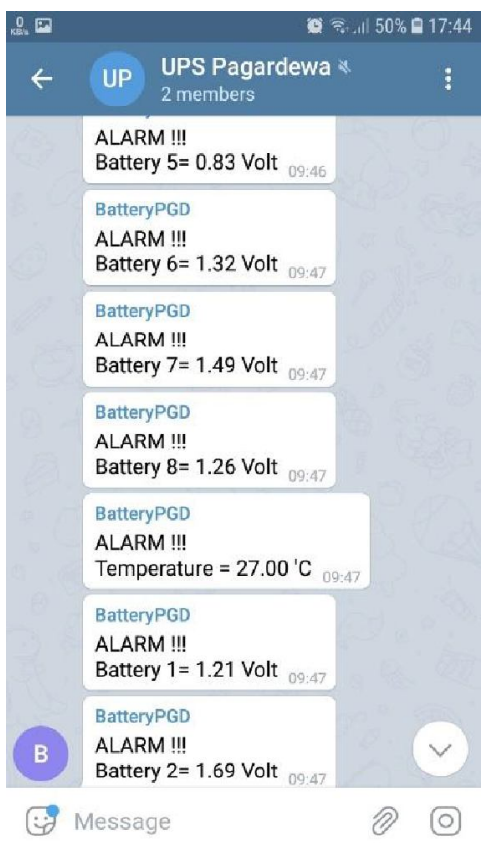

(b)

Figure 7: Display of Telegram application: (a) overall information and its command, (b) notification message when there is parameter value beyond its expected value

Table 3 shows the measurement results and its comparison to the commercial data where $\Delta$ and $p$ were calculated using equation (1) and (2) respectively. The test was conducted between 13.00 and $16.30 \mathrm{pm}$ of west Indonesian time (Jakarta time). In the table, only results for battery number 61 were included and how to do measurement, make comparison and calculate measurement difference are the same for battery number 62 until 68. The test results presented in Table 1 shows that the measurement difference average for temperature of battery room is $0.6{ }^{\circ} \mathrm{C}$ or equal to $3.03 \%$ while for voltage of battery number 61 is $0.0098 \mathrm{~V}$ or equal to $0.442 \%$. By using the same way, all battery measurement differences could be calculated as can be seen in Table 4.The test results showed that the final measurement difference for battery number 61 to 68 is equal to $0.0082 \mathrm{~V}$ or equal to $0.1896 \%$. 
Heru Supriyono et al., International Journal of Advanced Trends in Computer Science and Engineering, 9(4), July - August 2020,5376 - 5383

Table 3: Test results of battery temperature room and voltage measurement for battery number 61

\begin{tabular}{|c|c|c|c|c|c|c|c|c|}
\hline \multirow{2}{*}{ Time } & \multicolumn{4}{|c|}{ Temperature $\left({ }^{\circ} C\right)$} & \multicolumn{3}{c|}{ Voltage Battery No. 61 (V) } \\
\cline { 2 - 9 } & $c$ & $a$ & $\Delta$ & $p$ & $c$ & $a$ & $\Delta$ & $p$ \\
\hline 13:00:06 & 19.8 & 19 & 0.8 & 4.04 & 2.211 & 2.20 & 0.011 & 0.497 \\
\hline $13: 15: 11$ & 19.8 & 19 & 0.8 & 4.04 & 2.219 & 2.20 & 0.019 & 0.856 \\
\hline $13: 30: 27$ & 19.8 & 19 & 0.8 & 4.04 & 2.217 & 2.21 & 0.007 & 0.315 \\
\hline $13: 45: 32$ & 19.8 & 19 & 0.8 & 4.04 & 2.212 & 2.21 & 0.002 & 0.090 \\
\hline $14: 01: 00$ & 19.8 & 19 & 0.8 & 4.04 & 2.212 & 2.20 & 0.012 & 0.542 \\
\hline $14: 15: 10$ & 19.8 & 19 & 0.8 & 4.04 & 2.214 & 2.20 & 0.014 & 0.632 \\
\hline $14: 30: 30$ & 19.8 & 20 & 0.2 & 1.01 & 2.216 & 2.21 & 0.006 & 0.270 \\
\hline $14: 45: 21$ & 19.8 & 19 & 0.8 & 4.04 & 2.213 & 2.20 & 0.013 & 0.587 \\
\hline $15: 00: 58$ & 19.8 & 19 & 0.8 & 4.04 & 2.219 & 2.21 & 0.009 & 0.405 \\
\hline $15: 15: 07$ & 19.8 & 19 & 0.8 & 4.04 & 2.216 & 2.21 & 0.006 & 0.270 \\
\hline $15: 30: 22$ & 19.8 & 19 & 0.8 & 4.04 & 2.216 & 2.20 & 0.016 & 0.722 \\
\hline $15: 45: 13$ & 19.8 & 20 & 0.2 & 1.01 & 2.210 & 2.20 & 0.010 & 0.452 \\
\hline $16: 00: 44$ & 19.8 & 20 & 0.2 & 1.01 & 2.218 & 2.20 & 0.018 & 0.811 \\
\hline $16: 15: 08$ & 19.8 & 20 & 0.2 & 1.01 & 2.213 & 2.21 & 0.003 & 0.135 \\
\hline $16: 30: 14$ & 19.8 & 20 & 0.2 & 1.01 & 2.211 & 2.21 & 0.001 & 0.045 \\
\hline \multicolumn{3}{|c|}{ Minimum } & 0.2 & 1.01 & Minimum & 0.001 & 0.045 \\
\hline \multicolumn{3}{|c|}{ Maximum } & 0.8 & 4.04 & Maximum & 0.018 & 0.811 \\
\hline \multicolumn{3}{|c|}{ Average } & 0.6 & 3.03 & Average & 0.009 & 0.442 \\
\hline
\end{tabular}

Table 4:Summary of voltage measurement average $\Delta$ and $p$ for battery no.61-68

\begin{tabular}{|c|c|c|c|c|c|c|c|c|c|}
\hline Battery No. & $\mathbf{6 1}$ & $\mathbf{6 2}$ & $\mathbf{6 3}$ & $\mathbf{6 4}$ & $\mathbf{6 5}$ & $\mathbf{6 6}$ & $\mathbf{6 7}$ & $\mathbf{6 8}$ & Final Average \\
\hline Average $\Delta(\mathrm{V})$ & 0.0098 & 0.0129 & 0.0126 & 0.0040 & 0.0040 & 0.0045 & 0.0138 & 0.0042 & 0.0082 \\
\hline Average $p(\%)$ & 0.4424 & 0.5837 & 0.5717 & 0.1836 & 0.1807 & 0.2047 & 0.6258 & 0.1896 & 0.1896 \\
\hline
\end{tabular}

\section{CONCLUSION}

The monitoring system for battery voltage of UPS and battery room temperature for Pagardewa compressor station has been obtained. The system was able to measure the battery voltage during its normal operation and then presented the measured data in the website continuously and graphically in the period of 15 minutes. The graphical user interface of the web is equipped with detailed information of year, month, day, hour, minute, and second in order to facilitate online monitoring especially for maintenance purposes. The overall test results showed that the monitoring system able to measure the voltage of battery with average measurement difference of $0.0082588 \mathrm{~V}$ or equal to $0.37281315 \%$ compared to that of by a commercial measuring instrument while for battery room temperature is $0.6{ }^{\circ} \mathrm{C}$ or equal to $3.03 \%$. When either battery voltage or battery room temperature exceeds its specified range, the proposed monitoring system was able to send notification to Telegram application continuously every 75 seconds. These testing results suggested that the system is potentially to be applied on a larger scale involving all 108 batteries of UPS in Pagardewa compressor station. However, the proposed system still has weaknesses in that it could not monitor the SOC of the battery for possible replacement prediction. This issue should be addressed in the future works.

\section{REFERENCES}

1. T. Vantuch, J. Fulne cek, M. Holuša, S. Mišák, and Jan Vaculík. An examination of thermal features' relevance in the task of battery-fault detection, Applied Sciences 2018, vol. 8, pp. 1-16, 2018. https://doi.org/10.3390/app8020182

2. D. R. Pralad, B. H. Reddy, G. N. Varma, V. S. Kiran, and D. A. Shobharani.IoT based water monitoring and alerting system, International Journal of Advanced Trends in Computer Science and Engineering (IJATCSE), vol. 9, no. 2, pp. 1762-1766, April 2020. https://doi.org/10.30534/ijatcse/2020/131922020

3. A. Raghini, K. Karvendhan, V. C. Santhvel, V. S. Sindupriya, and A. Sivasakhti. IoT based soldier monitoring system with automatic temperature adjust suit, International Journal of Advanced Trends in Computer Science and Engineering (IJATCSE), vol. 9, no. 2, pp. 2438-2442, April 2020. https://doi.org/10.30534/ijatcse/2020/230922020

4. H. Supriyono, U. Bimantoro, and K. Harismah.Design, construction and testing of portable systems for temperature, humidity and ammonia monitoring of chicken coop, IOP Conference Series: Materials Science and Engineering, vol. 771 (2020) 012003, pp. 1-8, 2020.

5. N. Azman, M. K. A. Ghani, S. R. Wicaksono, and L. Salahuddin. The development of IoT tele-insomnia framework to monitor sleep disorder, International Journal of Advanced Trends in Computer Science and 
Engineering (IJATCSE), vol.8, no.6, pp. 2831-2839, December 2019.

https://doi.org/10.30534/ijatcse/2019/25862019

6. A. Zainuri, U. Wibawa, M. Rusli, R. N. Hasanah, and R. A. Harahap.VRLA battery state of health estimation based on charging time, TELKOMNIKA, vol.17, no.3, pp.1577-1583, Jun 2019.

7. X. Han, X. Feng, M. Ouyang, L. Lu, J. Li, Y. Zheng, and Z. Li.A comparative study of charging voltage curve analysis and state of health estimation of Lithium-ion batteries in electric vehicle, Automotive Innovation, vol. 2019, no. 2, pp. 263-275, 2019.

8. N. Agarwal, P. Saraswati, A. Malik, and Y. K. Bhateshvar.Design a battery monitoring system for lead-acid battery, International Journal of Creative Research Thoughts (IJCRT), vol. 2017, pp. 306-311, 2017.

9. N. S. S. Mohamed, N. F. B. A. Ghani, and N. F. A. Hamid. Battery monitoring for stand-alone photovoltaic system, Journal of Physics: Conference Series, vol. 1432 (2020) 012054, pp. 1-9, 2019. https://doi.org/10.1088/1742-6596/1432/1/012054

10. P. M. Kumbar and S. Sunkara. Android based battery monitoring system for lithium ion batteries used in electric vehicles, International Journal of Advanced Research in Electrical, Electronics and Instrumentation Engineering, vol. 7, no. 5, pp. 2495-2500, May 2018.

11. E. Soylu and R. Bayir.Measurement of electrical conditions of rechargeable batteries, Measurement and Control, vol. 49, no. 2, pp. 72-81, 2016.

12. C. Weng, Y. Cui, J. Sun, and H. Peng.On-board state of health monitoring of llithium-ion batteries using incremental capacity analysis with support vector regression, Journal of Power Sources, vol. 235, pp. 36-44, 2013.

13. S. A. Z. Murad, M. N. Md. Isa, and N. A. Rahman.Monitoring system for uninterruptible power supply, American Journal of Applied Sciences, vol. 4, no. 3, pp. 177-179, 2007.

14. K. V. Manasa, A. V. Prabu, M. S. Prathyusha, and S. Varakumari.Performance monitoring of UPS battery using IoT, International Journal of Engineering \& Technology, vol. 7, pp. 352-355, 2018.

15. A. Nuhic, J. Bergdolt, B. Spier, M. Buchholz, and K. Dietmayer.Battery health monitoring and degradation prognosis in fleet management systems, World Electric Vehicle Journal, vol. 9, pp. 1-20, 2018.

16. T. Sikora, L. Prokop, J. Fulneček, and T. Vantuch.Industrial uniterruptible power supply batteries monitoring augmentation by infrared camera, in 2019 20th International Scientific Conference on Electric Power Engineering (EPE), pp. 1-6, 15-17 May 2019.

https://doi.org/10.1109/EPE.2019.8777953

17. L. Lin, Y. Liu, W. Ping, and F. Hong.The electric vehicle lithium battery monitoring system, TELKOMNIKA, vol. 11, no. 4, pp. 2247-2252, Apr 2013.
18. V. Anudeep, C. Harshith, R. K. Paidi, C. R. Charan.Lithium battery monitoring and mathematically modelling its equation, International Journal of Recent Technology and Engineering (IJRTE), vol. 8, no. 2, pp. 699-702, July 2019.

19. R. Ulagadde and S.B. Jamge.Implementation of web based battery monitoring system, International Journal of Innovative Research in Science, Engineering and Technology, vol. 5, no. 8, pp. 14697-14703, Aug 2016.

20. M. H. A. Wahab, N. I. M. Anuar, R. Ambar, A. Baharum, S. Shanta, M. S. Sulaiman, S. S. M. Fauzi, and H. F. Hanafi.IoT-based battery monitoring system for electric vehicle, International Journal of Engineering \& Technology, vol. 7, pp. 505-510, 2018.

21. A. Rauniyar, M. Irfan, O. D. Saputra, J. W. Kim, A. R. Lee, J. M. Jang and S. Y.Shin.Design and development of a real-time monitoring system for multiple lead-acid batteries based on internet of things, Future Internet, vol. 9, pp. 1-16, 2017.

22. K. Friansa, I. N. Haq, B. M. Santi, D. Kurniadi, E. Leksono, and B. Yuliarto. Development of battery monitoring system in smart microgrid based on internet of things (IoT), Procedia Engineering, vol. 170, pp. 482-487, 2017. https://doi.org/10.1016/j.proeng.2017.03.077

23. R. V. Patil, D. Kalantre, N. Hirugade, A. More, and A. Kakade.Transformer health monitoring and control through arduino, International Journal of Electrical, Electronics and Data Communication, vol. 5, no. 1, pp. 59-62, Jan 2017.

24. D. Sarathkumar, M. Uvaraj, C. V. K. Kumar, and A. Kalaiselvi.Real time transformer health monitoring system using IoT, International Journal of Advanced Research in Science, Engineering and Technology, vol. 5, no. 11, pp. 7353-7359, Nov 2018.

25. P. G. Navamanikumar, S. Agnesha, P. Gowsalya, K.Indhu, and N.Sivasakthi.IoT based real time transformer health monitoring system and phase preventor, International Journal of Emerging Technologies in Engineering Research (IJETER), vol. 6, no. 4, pp. 119-124, Apr 2018.

26. R. S. S. Singh, B. S. S. Singh, S. A. Anas, and Y. Yunus.Continuous battery monitoring system (CBMS) for battery application, International Journal of Emerging Trends in Electrical and Electronics (IJETEE), vol. 11, no. 4, pp. 38-43, Aug 2015.

27. H. Supriyono and R. S. Kusuma.Telecontrol of alternating current motor with star delta starter using computer network, International Journal of Advanced Trends in Computer Science and Engineering (IJATCSE), vol. 9, no.34, pp. 2769-2774, May-June 2020.

https://doi.org/10.30534/ijatcse/2020/44932020 